\title{
Between solidarity and competitive threat?
}

\section{The ambivalence of anti-immigrant attitudes among ethnic minorities}

\author{
Cecil Meeusen ${ }^{\mathrm{b}}$, Koen Abts ${ }^{\mathrm{b}}$, and Bart Meuleman ${ }^{\mathrm{b}}$ \\ ${ }^{a}$ Department of Public Administration and Sociology, Erasmus University Rotterdam \\ ${ }^{\mathrm{b}}$ Centre for Sociological Research, KU Leuven \\ ${ }^{\mathrm{c}}$ Tilburg School of Social and Behavioural Sciences, Tilburg University \\ Corresponding address: \\ Parkstraat 45, 3000 Leuven \\ Cecil.Meeusen@kuleuven.be \\ Declarations of interest: none
}

Word count: 7831

Acknowledgements: The data collection of this project was made possible by the support of the National Science Foundation - FWO-Vlaanderen, the National Lottery, and The KU Leuven Research council. The first author received funding from the European Union's Horizon 2020 research and innovation programme under the Marie Skłodowska-Curie grant agreement No 707404 and from FWO-Vlaanderen (postdoctoral fellowship). 


\title{
Between solidarity and competitive threat?
}

\section{The ambivalence of anti-immigrant attitudes among ethnic minorities}

\begin{abstract}
Attitudes toward immigrants are typically investigated from the perspective of the dominant native majority group versus the subordinate ethnic minority group, but there are not apparent reasons why established minority groups would be exempt of negative attitudes towards new immigrant groups. This article investigates the roots of anti-immigrant attitudes among Belgians of Turkish and Moroccan descent. For that purpose, we analyze survey data from the Belgian Ethnic Minorities Elections Study 2014. Our results confirm that negative predispositions toward the arrival of new immigrants in general and Eastern Europeans in particular are also present among Turkish and Moroccan Belgians. Furthermore, we find that feelings of unfair treatment shape anti-immigrant attitudes in important ways. However, the direction of the relationship (positive vs. negative) depends crucially on the specific setting of unfair treatment. While perceived unfair treatment in the labor market arouses interminority hostility, experiences of unfair treatment by the government or in daily life lead to positive attitudes towards newcomers. Identification with the nation rather than with the ethnic group is significantly linked to more negative attitudes towards new immigrants in general (but not towards Eastern European immigrants). We furthermore find that the strength of the relationship between unfair treatment/identity and interminority attitudes depends on the particular immigrant group being evaluated.
\end{abstract}

Keywords: Interminority attitudes, perceived discrimination, relative deprivation, ethnic and national identity, Turks and Moroccans, Belgium 


\section{Introduction}

Attitudes toward immigrants are typically investigated from the perspective of the dominant native majority group versus the subordinate ethnic minority group (Blumer, 1958; Duckitt, 1992). However, continuing migration movements, originating from a wide range of places and characterized by different migration motives and legal statuses, have created substantial diversity within the non-native group, resulting in a situation of 'super-diversity' (Foner, Duyvendak, \& Kasinitz, 2019; Vertovec, 2007). The proliferation of diversities accentuates that research on intergroup relations and otherness should not be restricted to majority-minority relations, but has to broaden its scope to interminority attitudes as well (Callens, Valentová, \& Meuleman, 2014; Hindriks, Verkuyten, \& Coenders, 2015; Mustafa \& Richards, 2018; Sirin, Valentino, \& Villalobos, 2016; Verkuyten \& Martinovic, 2012). In this article, we therefore focus on the ambivalence of anti-immigrant attitudes among ethnic minorities specifically.

There is no apparent reason why well-established ethnic minority groups would be exempt from prejudices or exclusionist attitudes towards 'new immigrants' (Hindriks, Verkuyten, \& Coenders, 2014; Mustafa \& Richards, 2018; Sarrasin, Green, Bolzman, Visintin, \& Politi, 2018; Staerklé, Sidanius, Green, \& Molina, 2005). Roughly stated, there are two broad theoretical arguments concerning established ethnic minorities' attitudes towards new immigrants that lead to competing expectations (Craig \& Richeson, 2012, 2016; Just \& Anderson, 2015). A first approach relies on group conflict and social identity theory arguing that the origins of prejudice among both minority and majority groups are quite similar: perceived intergroup threat, group competition and the pursuit of a positive self-image are expected to instill anti-immigrant attitudes among ethnic minorities and the native population alike (Brylka, Jasinskaja-Lahti, \& Mähönen, 2016; Cortland et al., 2017; Hagendoorn, 1995; Oliver \& Wong, 2003). The second line of reasoning stresses solidarity and community ties between ethnic minority groups. After all, different ethnic minorities often share a background in migration, experiences with stigmatization, and a disadvantaged group position compared to the majority population, which might foster intergroup empathy and tolerant interminority attitudes (Cortland et al., 2017; Craig \& Richeson, 2016; Just \& Anderson, 2015; Sirin et al., 2016, 2017). Yet, there is still little research on this topic that can settle this issue empirically, certainly in comparison to the abundance of research on majority-group prejudices towards minority groups.

This article investigates the roots of anti-immigrant attitudes among Belgians of Turkish and Moroccan descent. We aim to contribute in four ways. Firstly, we investigate whether generic as well as minority-specific factors - such as feelings of unfair treatment and group identification (national and ethnic identification) - affect minority group members' attitudes towards immigrants and whether these experiences are catalysts for intergroup solidarity or rather intergroup competition. Secondly, we argue that unfair treatment can be experienced in different domains (e.g., in the labor market, politics, and daily life) and that depending on who is considered the competitor or challenger in that specific domain, 
different attitudinal reactions - in terms of solidarity or competitive threat - among ethnic minorities may occur. In other words, we expect the direction of the relationship (that is, positive or negative) between feelings of unfair treatment and attitudes toward immigration to depend on the domain in which unfair treatment is experienced. Thirdly, we adopt a differentiated threat approach acknowledging that different outgroups may challenge different interests and may therefore be prejudiced against for different reasons by different strata of the ingroup (Meuleman, Abts, Slootmaeckers, \& Meeusen, 2018). To test this idea, we focus on attitudes of the longer established Turkish and Moroccan minorities toward two ethnic outgroups: newly arriving immigrants in general and Eastern Europeans in particular. We expect that the strength of the relationship between feelings of unfair treatment and identity and immigrant attitudes depends on the immigrant group being evaluated by the established minorities. Fourthly, contrary to previous studies that often rely on general population surveys, we analyze survey data purposefully designed to measure attitudes of ethnic minority groups, namely the Belgian Ethnic Minorities Election Study 2014 (BEMES 2014; Swyngedouw, Meuleman, Abts, Bousetta, \& Galle, 2015). The major advantage of this design is that it is particularly adapted to capture minority attitudes and experiences, such as group discrimination and identity, and allows to analyze intergroup attitudes among two particular ethnic minority groups - i.e., Belgians of Turkish and Moroccan descent - rather than collapsing all respondents with a migration background into a single category.

\section{Ethnic minorities' attitudes toward immigrants: Solidarity or competitive threat?}

Empirical research shows that anti-immigrant attitudes are not only prevalent among the native majority group, but also among ethnic minorities (Callens et al., 2014; Hindriks et al., 2014; Mustafa \& Richards, 2018; Philip, Mahalingam, \& Sellers, 2010; Staerklé et al., 2005). Admittedly, anti-immigrant attitudes are less outspoken among ethnic minorities than among natives (Gorodzeisky \& Glikman, 2017; Sarrasin et al., 2018; Van der Zwan, Bles, \& Lubbers, 2017), but are nevertheless a relevant phenomenon to understand intergroup relations in superdiverse societies. The presence of negative inter-minority attitudes may be an indication that established ethnic minority members' position toward newcomers strikes a balance between threat and solidarity. To understand this paradoxical phenomenon, the point of departure of our study is that anti-immigrant attitudes among ethnic minorities cannot be understood without taking into account their dual position in Western societies, in terms of socialstructural position, group position and self-identification. On the one hand, ethnic minorities are citizens of the countries they live in - and, to a certain extent, they also identify as such (Verkuyten \& Martinovic, 2012) - although they tend to occupy disadvantaged positions in socio-economic and cultural respect (Timmerman, Vanderwaeren, \& Crul, 2003). Because of their vulnerable position, they are among the first to experience or perceive zero-sum competition and identity threat emanating from the arrival of new immigrant groups, which can induce prejudiced attitudes toward these groups 
(Semyonov, Raijman, \& Yon-Tov, 2002). In that respect, the underlying group conflict and social identity mechanisms generating prejudice seem to run in parallel for majority and minority groups (Hindriks, Verkuyten, \& Coenders, 2017; Sarrasin et al., 2018; Van der Zwan et al., 2017). On the other hand, established minority group members share a number of constitutive characteristics with newcomers, such as experiences related to having a migration background, moving to another country, occupying subordinate social positions compared to the dominant group, stigmatization, discrimination and, in some cases, cultural or community ties. According to the logic of shared experiences and kinship, these similarities could create a 'common disadvantaged (ethnic) identity' and intergroup empathy, facilitating feelings of solidarity and attenuating negative attitudes towards newcomers (Cortland et al., 2017; Craig \& Richeson, 2012, 2016; Gay, 2006; Mustafa \& Richards, 2018; Semyonov et al., 2002; Sirin et al., 2016). However, the question remains which side of this dual position gains the upper hand: Are ethnic minorities' attitudes towards immigrants shaped by a logic of intergroup threat or by a logic of subordinate ethnic minority solidarity?

The few studies that have investigated interminority prejudice in Western Europe distinguish between two types of mechanisms that affect attitudes towards newcomers. Generic mechanisms operate in a similar way among minorities and majorities. Dissatisfaction about the state of the economy (Just \& Anderson, 2015), economic threat (Sarrasin et al., 2018), a low socioeconomic status (Gorodzeisky \& Glikman, 2018; Van der Zwan et al., 2017), particular ideological beliefs (Just \& Anderson, 2015) and a lack of intergroup contact (Brylka et al., 2016; Hindriks et al., 2014; Philip et al., 2010) fuel intergroup prejudices among majority and minority group members alike. Besides these generic mechanisms, minority group members may share particular characteristics and experiences that might be relevant to understand their intergroup attitudes. Examples include the acquired citizenship status (Hindriks et al., 2014; Just \& Anderson, 2015), time of residence in the host country (Mustafa \& Richards, 2018; Van der Zwan et al., 2017) and social identification (Hindriks et al., 2014; Philip et al., 2010; Sarrasin et al., 2018; Staerklé et al., 2005; Verkuyten \& Martinovic, 2012).

In our study, we emphasize two sets of (minority specific) predictors, namely (1) perceptions of unfair treatment; and (2) national and ethnic identification. These predictors capture the essence of the dual position of established minority groups in terms of relative group position as well as selfidentification. Although similar variables are sometimes used to explain anti-immigrant attitudes among natives as well, we assume that among established ethnic minorities the puzzle is more complex because of their dual position. The crucial question is: do these mechanisms of unfair treatment and identification translate in intergroup solidarity or rather intergroup threat toward new immigrants? 


\section{Perceptions of unfair treatment}

Research demonstrates that experiences of unfair treatment, such as perceived group discrimination and group relative deprivation (i.e., the perception that one's group is not accepted and treated unfairly compared to another group), are of crucial importance to understand intergroup attitudes and behaviors of minorities (Gay, 2006; Monteith \& Spicer, 2000; Tropp \& Pettigrew, 2005). Whereas among majority group members relative deprivation theory (Runciman, 1966) predicts that feelings of group relative deprivation induce negative attitudes toward the threatening outgroup (Pettigrew et al., 2008; Meuleman et al., 2018), in this article, we argue that among ethnic minorities the relationship between feelings of unfair treatment and anti-immigrant attitudes can be either positive or negative, depending on the dominant underlying logic - i.e., threat or solidarity.

On the one hand, group conflict theory explains that competition over scarce resources (such as jobs, housing, welfare, political power and social status) creates perceptions of being threatened, which in turn leads to prejudiced intergroup attitudes (Bobo, 1983; Jackson, 1993). In that sense, negative attitudes towards other groups are a consequence of 'a sense of group position' (Blumer, 1958): individuals define themselves as members belonging to a social group relative to other (ethnic) groups involved in a perceived zero-sum game. According to this logic, the arrival of new immigrants who challenge the collective interests and the just position of an established ethnic minority group in the social order, will result in persistent prejudices towards the newcomers. On the other hand, while they might have a favorable status compared to new immigrants, established immigrant communities still occupy a relatively disadvantaged, low status position in majority-minority relationships. As such, ethnic minorities share with new immigrants social experiences of exclusion, deprivation and devaluation relative to natives (Lafleur \& Marfouk, 2018; Meeusen \& Jacobs, 2017). Being considered as a threat to the prerogatives of the majority group may activate a sense of commonality, solidarity and kinship with other minority groups who are in a similar vulnerable position (Cortland et al., 2017; Craig \& Richeson, 2012; Just \& Anderson, 2015; Mustafa \& Richards, 2018). Group Empathy Theory predicts that shared feelings of unfair treatment and discrimination among different minority groups may get these groups to look past their differences (such as objective or perceived competition over scarce resources) to a point where empathy improves intergroup attitudes (Sirin et al., 2016, 2017). Such sense of solidarity and empathy implies that perceptions of unfair treatment are likely to stimulate tolerance toward immigrants, rather than fuel prejudice as the threat logic assumes (Semyonov et al., 2002).

Perceived discrimination and relative deprivation could thus set off threat as well as solidarity reactions towards new immigrants among established minority groups. Which logic gains the upper hand ultimately depends on the comparison group the ethnic minorities have in mind when evaluating their own group position (Blumer, 1958). Unfair treatment may occur in different settings and domains. 
Attitudinal reactions to relative deprivation and discrimination will be targeted at who is considered as the agent of competition and the usurper of the ingroup's resources (Monteith \& Spicer, 2000; Van Pottelberge \& Lievens, 2017). As a result, feelings of unfair treatment in the labor market can have different consequences for intergroup attitudes compared to unfair treatment by governmental agencies. We expect that ethnic minorities' feelings of threat in the labor market are primarily induced by other ethnic minorities and immigrants, who are seen as direct competitors in the same segment of the labour market - that is, jobs typically characterized by low status, high insecurity and poor working conditions (Just \& Anderson, 2015; Gay, 2006; Huber \& Oberdabernig, 2016; Phalet \& Swyngedouw, 2003; Timmerman et al., 2003; Van der Zwan et al., 2017). As other economically vulnerable (ethnic minority) groups are likely to be seen as the competitors here, the threat logic might gain the upper hand. Consequently, we hypothesize that feelings of unfair treatment in the labour market are positively related to anti-immigrant attitudes $(\mathrm{H} 1)$.

Experiences of being treated unfairly by governmental agencies, conversely, could set off an opposite mechanism. Because government agencies can be seen as representative of the dominant native group, the latter is likely to be perceived as a source of competition. Ethnic minorities might blame the native group for their disadvantaged position in institutional settings, which can bring them closer to groups with similar experiences (i.e., the solidarity logic). Therefore, we hypothesize that feelings of unfair treatment by governmental agencies are negatively related to anti-immigrant attitudes $(\mathrm{H} 2)$. In their study on the causes of group empathy, Sirin and colleagues (2017) indeed show that experiences of unfair treatment by law enforcement exhibited higher levels of empathy between ethnic minority groups, while perceived economic competition was negatively associated with group empathy.

A third important domain of potential unfair treatment refers to daily life experiences on the streets, in restaurants, in supermarkets or on public transport. Assuming that ethnic minorities hold natives rather than other ethnic minorities accountable, ${ }^{1}$ unfair treatment in daily life can activate perceptions of communality and empathy with other oppressed or discriminated groups, i.e., the logic of solidarity (Craig \& Richeson, 2016; Mustafa \& Richards, 2018; Sirin et al., 2016). Yet feelings of exclusion and overt discrimination may also cause social identity threat and elicit a defensive reaction in the form of interminority bias (Cortland et al., 2017). In other words, in order to restore a positive social identity and group-esteem caused by experiences of daily life negative treatment, ethnic minority groups may start devaluing other minority groups (Brylka et al., 2016). Cortland and colleagues (2017) and Craig and Richeson (2016) argue that the direction of the relationship between feelings of unfair treatment and interminority prejudice depends on whether the minority groups are stigmatized along the same or across different identity dimensions. While the latter case may foster social identity threat, the former

\footnotetext{
${ }^{1}$ Althoug it is of course possible that ethnic minorities feel treated unfairly by other minority groups, various studies have shown that natives are often identified as the main source of discrimination (Coenders, Boog, \& Dinsbach, 2010; Vandezande, Fleischmann, Baysu, Swyngedouw, \& Phalet, 2009).
} 
may elicit positive, inclusionary attitudes (Craig \& Richeson, 2012). Since ethnic minorities and new immigrants are both racial minorities, and thus share a prominent identity dimension, we expect that feelings of unfair treatment in daily life are negatively related to anti-immigrant attitudes (H3). In sum, while we expect a logic of competitive threat for unfair treatment in the labor market, we expect a logic of solidarity for unfair treatment by governmental agencies and in daily life.

\section{National and ethnic identification}

Regarding self-identification, established minorities occupy a dual position as they can identify with the host nation and/or the ethnic community (Verkuyten \& Martinovic, 2016). Similar to perceptions of unfair treatment, the relationship between interminority attitudes and identification can follow a logic of solidarity and/or threat depending on whether minorities identify primordially with the host nation, the ethnic community or both. According to acculturation theory, assimilated ethnic minority group members (that is, those who identify stronger with the host country rather than with the ethnic group) consider themselves as part of the majority group and can therefore legitimately claim certain material and immaterial resources. New immigrants are seen as outsiders and a threat to the prerogatives of the assimilated minorties, which activates negative attitudes towards these new immigrants (Alanya, Swyngedouw, Vandezande, \& Phalet, 2017; Blumer, 1958). Similarly, assimilated ethnic minorities are also more likely to adapt to the dominant social norms and values prevalent in the native population (Sarrasin et al., 2018; Van der Zwan et al., 2017), including the negative stereotyping of immigrants, which leads to the alignment of their intergroup attitudes with those of the natives (Verkuyten \& Martinovic, 2012). As natives generally tend to be less open toward immigrants than established ethnic minorities (Sarrasin et al., 2018), we expect that ethnic minorities who exclusively identify with the host nation are more likely to hold more negative attitudes toward immigrants than ethnic minorities who also or exclusively identify with their ethnic group. National identification, as an indicator of psychological integration (De Vroome, 2013; Esser, 2003), can thus bring along the adoption of threatinduced prejudices among ethnic minority members. In support of this argument, Just and Anderson (2015) show that immigrants with formal citizenship in the host country are more prejudiced toward immigration compared with noncitizen immigrants. Similarly, Van der Zwan and colleagues (2017) conclude that the longer immigrants reside in the host country - implying longer exposure to native norms and values and fading of their own immigration experience -, the stronger their perceptions of migrant threat. Conversely, a strong ethnic identification can reduce the social distance towards other ethnic outgroups, and therefore stimulate interminority solidarity. A stronger ethnic identity might foster an 'achieved sense of the ethnic self that provides the basis for acceptance and openness to other groups and cultures' (Hindriks et al., 2014, p. 68). Hindriks and colleagues (2014) indeed find that a stronger ethnic identification was associated with less social distance between ethnic groups, but greater 
ingroup positivity as well. According to these arguments, we expect that established ethnic minorities with an exclusive national identification are more negative towards new immigrants compared to individuals with a mixed or exclusive ethnic identity $(\mathrm{H} 4)$.

\section{Contextualizing interminority attitudes: The case of Turkish and Moroccan Belgians}

This paper tests the above-mentioned general hypotheses in the specific case of the Turkish and Moroccan communities in Belgium. Following the differentiated threat approach (Meuleman et al., 2018), we argue that anti-immigrant attitudes are idiosyncratic to specific constellations of intergroup relations. In other words, we expect that the concrete realization of attitudes towards particular outgroups is dependent on the structural position of the ingroup vis-à-vis the outgroup and the specific setting of the ingroup-outgroup relations. As such, intergroup attitudes are always embedded in a social space as particular intergroup configurations, competitive contexts and cultural settings shape the intensity as well as contents of prejudice (Gorodzeisky \& Glikman, 2018; Hellwig \& Sinno, 2017; Meeusen \& Kern, 2016; Meuleman et al., 2018). This implies that Turkish and Moroccan Belgians' attitudes towards immigrants may vary according to the ethnic outgroup at stake and its characteristics. Therefore, understanding interminority attitudes of the Turkish and Moroccan Belgians requires that their social, economic and cultural positions in Belgian society are contextualized.

In Belgium, Turkish and Moroccan communities have their roots in the post-war migration that was actively organized by the Belgian state to secure sufficient labor force in the coalmines and industry. Even after government-driven labor migration was stopped in 1974, the inflow of Turkish and Moroccan nationals continues until today, mainly through the mechanism of marriage migration and family reunification. In 2016, among the Belgians population born outside Belgium, the Turkish (5.5\%) and Moroccan (11.6\%) communities are the largest national groups coming from non-EU countries (Lafleur \& Marfouk, 2018; Myria, 2017). Most Moroccans and Turks in Belgium are (cultural) Muslims. The second and third generation descendants often occupy disadvantaged socio-economic positions and are one of the most vulnerable groups on the labor market: compared to the Belgian natives, non-EU citizens are almost two to three times more likely to be unemployed (Corluy, Haemels, Marx, \& Verbist, 2015). Being an economically disadvantaged and culturally visible and distinct minority group, Turkish and Moroccan communities are often perceived as a threat for low-skilled jobs, social welfare provisions and the established social-cultural order (Abts \& Kochuyt, 2013). Furthermore, these groups are often target of prejudice and discrimination on the labor and housing market, further consolidating their socio-economic vulnerability (Alanya et al., 2017). Thus, notwithstanding their lengthy presence in Belgium, the established Turkish and Moroccan communities occupy a low position in the ethnic hierarchy (Meeusen \& Jacobs, 2016; Meuleman \& Billiet, 2003), illustrating their dual position as being Belgian citizens who legally enjoy equal rights as native citizens, 
but at the same time remain outsiders socially, economically and culturally. Although both groups share a similar history of immigration, structural disadvantages and negative stereotyping (Alanya et al., 2017), there are some differences between both communities as well. Generally, Moroccan Belgians are the most stigmatized group and report higher levels of discrimination than Belgians of Turkish descent (Alanya et al., 2017). Moroccans also have a stronger religious identity than ethnic identity (Fleischmann \& Phalet, 2016), while Turkish Belgians have stronger connections to their ethnic community (Jacobs, Phalet, \& Swyngedouw, 2004). They also differ in their social-structural position: while Moroccan immigrants are better integrated in the Belgian education system than the Turkish immigrants, they are less integrated in the labour market (Gsir, Mandin, \& Mescoli, 2015).

Besides Turkish and Moroccan immigrants, Belgium has over the last decades experienced immigration inflows from many different origin countries, resulting in a super-diverse society (Vertovec, 1997) with an unprecedented variety of co-existing communities with different cultures, faiths, legal statuses and migration motives (Hooghe, Trappers, Meuleman \& Reeskens, 2008). From the perspective of the longer established Turkish and Moroccan communities in Belgium, intergroup relations with more recently arrived Eastern European immigrants are of particular relevance. Since the fall of the Iron Curtain, the presence of Polish, Bulgarian and Romanian immigrants in Belgium increased exponentially. Anno 2017, the Romanians and Poles occupy respectively the eighth (4.2\%) and ninth place (4.0\%) of immigrants born outside Belgium (Lafleur \& Marfouk, 2018). These new immigrants often arrived in neighborhoods and labor market segments with a strong Turkish and Moroccan presence. At the same time, differences in religious background and language accentuate cultural differences between these groups.

As mentioned, according to the differentiated threat model (Meuleman et al., 2018), prejudice towards various outgroups might stem from different origins. In the context of interminority attitudes, this model assumes that perceived discrimination and self-identification may influence Turkish and Moroccan attitudes towards various outgroups differently. In this regard, the comparison of attitudes towards the specific group of Eastern European newcomers with attitudes towards new immigrants in general can yield additional insights in the genesis of interminority attitudes. Given the particular intergroup context sketched above, one can expect that Turkish and Moroccan Belgians perceive especially the presence of Eastern European immigrants in terms of competition, thereby reinforcing the logic of competitive threat. Negative attitudes stemming from feelings of labor-related deprivation (see H1), for example, might be directed in the first place at Eastern Europeans, and less so towards new immigrants in general. At the same time, cultural differences between the Turkish and Moroccan communities on the one hand, and Eastern European immigrants on the other hand, might obstruct the logic of solidarity. Therefore, the the logic of solidarity in case of perceptions of unfair treatment by governmental agencies (see H2) and in daily life (see H3) might be weaker when Eastern European immigrants are the target group compared to new immigrants in general. 


\section{Data and methods}

\section{Dataset: Belgian Ethnic Minorities Election Study}

To test the hypotheses, we use data from the Belgian Ethnic Minorities Election Study (BEMES) (Swyngedouw et al., 2016), a probability-based survey of Belgian citizens of Turkish or Moroccan descent collected by means of computer assisted personal interviews (CAPI). The population consists of first and second-generation migrants from Turkey or Morocco, 18 years and older with the Belgian nationality, living in Antwerp (largest city in Dutch-speaking part of Belgium) or Liège (largest city in French-speaking part of Belgium). The sampling frame was based on the register information (name, address, sex, age, and ethnic background) of the two city administrations. Ethnic background was not defined by self-categorization, but by means of information on the parents place of birth included in the municipal population registers. In total 878 completed surveys were collected $(50.9 \%$ female, $50.9 \%$ Turkish; response rate $38.1 \%$ ).

\section{Measurements}

Attitudes toward immigrants were assessed with four Likert-items (5-point agree-disagree items). Two items tapped attitudes toward (new) immigrants in general (i.e., without reference to a specific immigrant group): 'There should be stricter regulations to make it more difficult for migrants to get their family to come here' and 'The borders should be closed because there are too many migrants already in Belgium'. Two other items probed about opinions toward Eastern Europeans in particular: 'Migrants from Eastern Europe are taking our jobs' and 'Migrants from Eastern Europe are ruining the reputation of migrants who lived here before they did'. The correlation between the two latent factors is 0.606 , indicating that the two constructs are strongly correlated but distinguishable.

Feelings of unfair treatment were measured in three different domains: in the institutional, professional and social sphere. First, feelings of unfair treatment by governmental agencies were measured with four Likert-type items (5-point agree-disagree items): two items about (perceptions of) (un)equal treatment by the government and two about (perceptions of) (un)equal treatment by the local social assistance agency (OCMW/CPAS). Second, three Likert-type items (5-point agree-disagree items) about difficulties in finding a steady job and perceptions of inequality in the job market tapped feelings of unfair treatment at the labor market. Third, to measure unfair treatment in daily life respondents were asked to indicate how often (never, rarely, sometimes, regularly, often) that people of their descent experience hostility and discrimination because of their descent in Belgium (1) at school or at the workplace, (2) when going out in dancing's, cafés or restaurants, and (3) on the street or in public transport. Importantly, all the items referred to perceptions of discrimination/deprivation of the 
respondent's ingroup and thus tap feelings of unfair treatment of one's group and not as an individual, accentuating (ethnic/social) group comparisons.

All latent factors were validated with confirmatory factor analysis, of which the results, together with the full wording of the items, are presented in Appendix 1. All factor loadings are sufficiently strong (all >.55, most >.70), and the measurement model including all latent factors has a good fit $\left(\mathrm{X}^{2}\right.$ $=239, \mathrm{df}=67, \mathrm{RMSEA}=0.054, \mathrm{CFI}=0.964, \mathrm{TLI}=0.951)$.

National and ethnic identification were measured by asking respondents whether they feel mostly Belgian, rather Turkish or Moroccan, or somewhere in between. They could indicate their feelings of connectedness on a six-point scale: 1 = 'I only feel Turkish/Moroccan' (3\%); 2 = 'I feel more Turkish/Moroccan than Belgian' (16\%); 3 = 'I feel equally Turkish/Moroccan as I feel Belgian (52\%)'; 4 = 'I feel more Belgian than Turkish/Moroccan' (18\%); 5 = 'I only feel Belgian (2\%); and 6 = 'I do not feel truly Turkish/Moroccan nor truly Belgian’ (7\%). We collapsed category 1 and 2, and category 4 and 5 and use identification as a four-category nominal variable in the explanatory model, acknowledging that ethnic and national identification are not mutually exclusive. In sum, 19\% of the Turkish and Moroccan Belgians feel only or mostly connected to their ethnic group, whereas $20 \%$ feels only or mostly connected to the national group; the majority feels connected to both the ethnic and national group; 7\%, finally, feels disconnected from both the ethnic and national group.

Several other variables can affect interminority attitudes and could confound the relationship between unfair treatment, national/ethnic identification and evaluations of immigrant groups. Previous research links a range of individual characteristics of minority members - such as demographics, socioeconomic status, generational status, and religious involvement - to minorities' attitudes towards immigration (Hindriks et al., 2014; Just \& Anderson, 2015; Philip et al., 2010; Van der Zwan et al. 2017). Therefore, we included various indicators of the socio-structural position of the Turkish and Moroccan Belgians as control variables: region ( $0=$ Antwerp, $1=$ Liège; $54,9 \%$ Antwerp $)$; gender $(0$ = Male, $1=$ Female; 49.1\% male), ethnic background ( 0 = Moroccan, $1=$ Turkish; 49.1\% Moroccan $)$, education (six-point scale: no degree, lower education, lower secondary education, higher secondary education, tertiary education non-university, tertiary education university - included as a continuous indicator; $\mathrm{M}=3.63, \mathrm{SD}=1.04$ ), and age (in years; $\mathrm{M}=32.50, \mathrm{SD}=11.34$ ). Generation was subdivided in three categories: $1^{\text {st }}$ generation are migrants born abroad who migrated to Belgium after the age of $15(16.7 \%) ; 1,5^{\text {th }}$ generation are migrants born abroad who migrated to Belgium before the age of 15 $(46.4 \%) ; 2^{\text {nd }}$ generation are migrants born in Belgium with at least one parent born in Morocco or Turkey (41.4\%) (Heath, Fisher, Rosenblatt, Sanders, \& Sobolewska, 2013). Religious practice was measured with three categories: not Muslim (i.e., not religious or practicing another religion than Islam) (12.2\%), non-practicing Muslim (46.4\%), and practicing Muslim (41.4\%). To construct the latter category, a distinction between male and female respondents was made: a female respondent who 
reported to have always fasted during the last Ramadan and to pray at least five times per day was categorized as a practicing Muslima. For male respondents to be categorized as a practicing Muslim it was additionally required that they reported to visit the mosque at least weekly. Finally, two indicators of respondent's economic capital were included. First, income (in)security was operationalized by asking respondents which of the following situations described their financial situation best: enough income and able to save money (36.6\%), just enough income to make ends meet (43.1\%), not enough income and regularly troubles to make ends meet (20.3\%). Second, respondents were asked whether they or anyone else in the household had received welfare benefits in past two years $(0=\mathrm{Yes}, 1=\mathrm{No}$; $53.1 \%$ yes).

\section{Analytical strategy}

To gain insight in the interplay between the various sets of predictors we estimate two MIMIC (Multiple Indicator Multiple Causes) models. In the first model, we assess the relationship between the control variables and the two variants of anti-immigrant attitudes (toward new migrants in general respectively Eastern Europeans). In the second model, we add the latent factors for feelings of unfair treatment in the labor market, by governmental agencies and in daily life, as well as theidentity indicator (ethnic versus national identification). Analyses were conducted based on the measurement model of which the results are presented in Appendix 1. We estimated all models with a robust weighted least squares estimator (WLSMV) in Mplus 7.3 to take the ordered-categorical nature of the latent factor indicators into account. In order to correct for unit nonresponse, post-stratification weights based on age, gender, ethnic background and city of residence were applied in all analyses. In addition, to deal with item nonresponse, we used multiple imputation for all variables. All reported parameters below are standardized, apart from the effects of the dummy variables, which are semi-standardized. As a result, the effects of dummy variables refer to the difference with the reference category in terms of standard deviations on the dependent variable.

\section{Results}

As expected, negative attitudes towards immigrants are present among our investigated ethnic minority groups. With regard to predispositions toward the arrival of new immigrants in general, $28 \%$ of the Turkish and Moroccan Belgians agrees that there should be stricter regulations for family reunification and 37\% thinks that borders should be closed because there are too many migrants in Belgium (see Appendix 1). The attitudes towards Eastern Europeans are quite negative as well, given that more than half of our respondents believe that Eastern European migrants take their jobs (55\%) and ruin the reputation of other migrants ( $53 \%)$. 
Table 1 present the results of the MIMIC explanation model for attitudes towards immigrants in general and Eastern European immigrants. What immediately stands out are the differentiated effects on the two anti-immigrant scales. We first discuss the findings of the control variables in Model 1. With regard to the social-structural indicators, in accordance with the findings of Just and Anderson (2015), female and older Belgians of Turkish and Moroccan descent express more negative attitudes toward new migrants in general. While older respondents are also somewhat more negative toward Eastern Europeans, gender is not related to prejudice towards Eastern Europeans. Contrary to previous findings of Van der Zwan and colleagues (2017) in the Netherlands, first and second generation Belgians of Turkish and Moroccan descent do not differ in their attitudes toward migrants in general neither toward Eastern Europeans. Consequently, our results do not confirm the general finding that the anti-immigrant attitudes of second-generation immigrants, with more durable bonds with the host country, would be substantially more negative than the attitudes of immigrants with a more recent immigration history (see Sarrasin, Green, Fasel \& Davidov, 2015; Valentova \& Berzosa, 2012). Regarding socio-economic status, respondents who think that their income is not enough to make ends meet score higher on antiEastern Europeans attitudes; while no relationship was found with attitudes toward new migrants. This relationship remains significant when perceptions of unfair treatment are taken into account as well (see Model 2). That is, the relationship between income insecurity and Eastern European attitudes is not mediated by feelings of unfair treatment. Educational level and being a recipient of welfare benefits are not significant predictors of both forms anti-immigrant attitudes. The assumption of realistic group threat theory that mainly longer-residing migrants in weak socio-economic positions - in terms of low education and income insecurity - would have more outspoken negative attitudes to new migrants is thus only partially confirmed. Region and ethnic background (Moroccan vs. Turkish) have no impact on minorities' anti-immigrant attitudes whatsoever. Only when feelings of unfair treatment and ethnic/national identification are taken into account, Belgians of Turkish descent are found to be slightly more negative toward Eastern Europeans than Belgians of Moroccan descent (Model 2). Furthermore, we find that religious involvement is related to attitudes towards the culturally more distant Eastern European group. Compared to those who are not religious, practicing Muslims have more negative attitudes toward Eastern Europeans, whereas there is no such effect on attitudes towards newly arriving migrants in general. This finding suggests cultural distance between established minorities and newcomers can play a role in the genesis of hostile interminority attitudes. In all, the socio-demographic variables explain more variation in attitudes toward Eastern Europeans (12.9\%) than attitudes towards migration in general $(9.9 \%)$.

Next, we turn to the predictors of main interest, namely feelings of unfair treatment and ethnic and/or national identification (see Model 2). Including these focal predictors nearly doubles the percentage explained variance (19.9\% for attitudes toward immigrants in general, and $20.3 \%$ for attitudes toward Eastern Europeans in particular). Regarding feelings of unfair treatment, our findings generally stress 
the dual position of ethnic minorities in Western Europe and make clear that ethnic competition/threat as well as kinship/solidarity mechanisms operate simultaneously (Craig \& Richeson, 2016; Just \& Anderson, 2015). With respect to labor-market related feelings of deprivation, hypothesis 1 is clearly confirmed: Turks and Moroccans who feel treated unfairly in the labor market express more negative attitudes toward migrants in general and towards Eastern Europeans. Interestingly, this relationship is stronger when Eastern European immigrants are concerned. Eastern Europeans can indeed be seen as an economically threatening outgroup for Belgians of Turkish and Moroccan descent. ${ }^{2}$ In a context of a zero-sum competition - as is the case in the labor market - the group conflict mechanism thus seems to be activated, that is, newcomers are more likely to be perceived as a competitive threat for scarce resources (like job opportunities) to the established minority group members, inducing negative attitudes toward immigrants.

In opposition to the mentioned competition mechanism active on the labor market, experiences of discrimination and deprivation in the institutional and social sphere seem to activate mechanisms of kinship and solidarity. Feelings of unfair treatment by governmental institutions is only related to attitudes toward migration in general, but in the direction as hypothesized (H2): the more one feels deprived by governmental agencies, the more positive one is toward new immigrants in general. Turks and Moroccans who experience more unfair treatment in their daily life (i.e., when going out, on the streets, in public transportation and among colleagues) hold less negative attitudes toward newly arriving migrants in general as well as Eastern Europeans, confirming hypothesis 3. In sum, our three hypotheses with regard to unfair treatment are largely confirmed: while the competitive threat logic is predominant for feelings of unfair treatment related to the labor market, we find the interminority solidarity logic to prevail for perceptions of discrimination by government and in daily life.

Regarding identification, results show that Turkish and Moroccan Belgians who feel more Belgian than Turkish/Moroccan have more negative attitudes toward new immigrants in general. These findings are in line with acculturation theory, which predicts that non-natives who feel mostly or only Belgian would adopt the higher levels of anti-immigrant prejudice of the native population, confirming $\mathrm{H} 4$. Regarding Eastern European immigrants, however, no effects of ethnic and national identification are found.

Importantly, our findings show that general anti-immigrant attitudes and attitudes towards Eastern European immigrants have partly different antecedents indicating to some extent that the origins of antiimmigrant attitudes are indeed idiosyncratic to the target group under study. This illustrates how different outgroups may challenge different interests and values. It seems to be that shared ethnic origin

\footnotetext{
${ }^{2}$ The stronger relationship between unfair treatment at the labor market and attitudes toward Eastern Europeans is not driven by the item probing about job competition with Eastern Europeans. A model without this item provides substantively similar conclusions.
} 
appears to have the power to buffer the effect of competitive threat on anti-immigrant attitudes, while strengthening the effects of solidarity. After all, the positive effect of perceived unfair treatment in the labor market on negative attitudes toward Eastern Europeans is stronger compared to attitudes towards migrants in general, while the negative relationship between unfair treatment by government and attitudes toward migrants in general is stronger than the relationship with attitudes towards Eastern Europeans.

As a test of the robustness of our findings, we additionaly estimated a model including two potentially confounding (political) attitudinal variables: authoritarianism and left-right ideology ${ }^{3}$. Authoritarian individuals are typically characterized by an uncritical submission to authority figures and adherence to conventional social values. As such, similar to rightist individuals, authoritarians tend to reject all kinds of deviant groups that are judged to challenge the social and cultural status quo (Feldman, 2015; Gorodzeisky \& Glikman, 2018). Authoritarianism ( $\beta=0.311, \mathrm{SE}=0.047$ for attitudes toward immigrants in general and $\beta=0.469, \mathrm{SE}=0.043$ for attitudes toward Eastern Europeans) and ideological position $(\beta=0.240, \mathrm{SE}=0.042$ for attitudes toward immigrants in general and $\beta=0.119$, $\mathrm{SE}=0.050$ for attitudes toward Eastern Europeans) are relevant predictors of both types of antiimmigrant attitudes. Importantly, including these predictors does not influence the relationship between feelings of unfair treatment, identity and anti-immigrant attitudes. More so, the relationships become slightly stronger and the effect of unfair treatment by the government on attitudes toward Eastern Europeans becomes significant $(\mathrm{p}=0.04)$.

\footnotetext{
${ }^{3}$ Authoritarianism was measured by means of three Likert-type items (5-point agree-disagree items) tapping the perceived importance of (1) the punishment of immoral persons, (2) obedience and respect for authority, and (3) strict laws. Left-right ideology was measured with a typical self-placement scale (11-point scale, $0=$ 'very leftwing', 10 = 'very right-wing'). The full model can be found in a supplementary online file.
} 


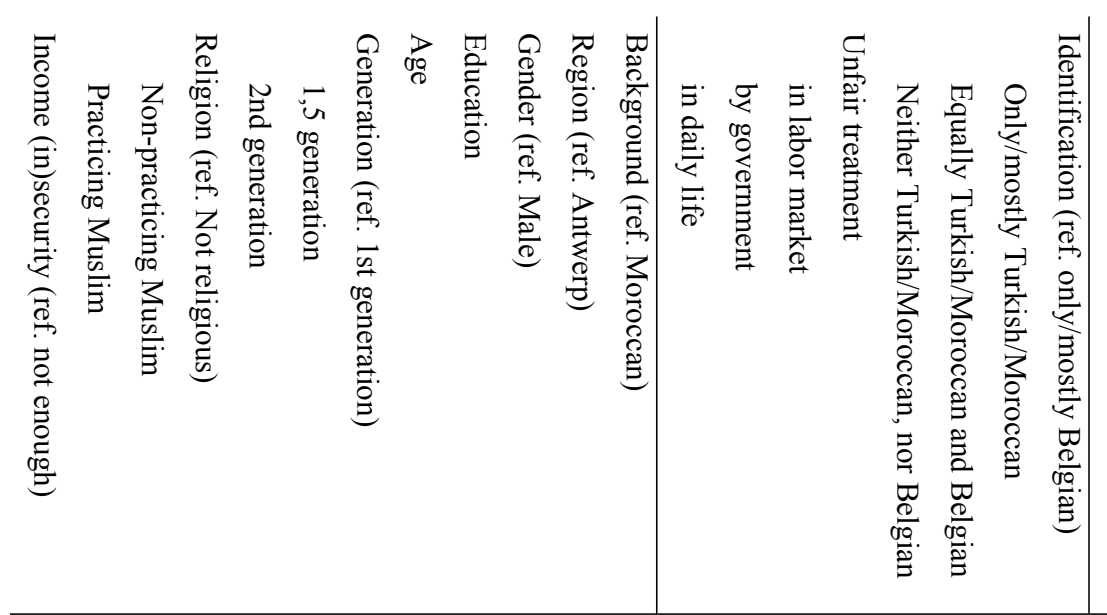

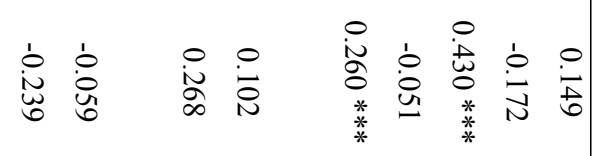

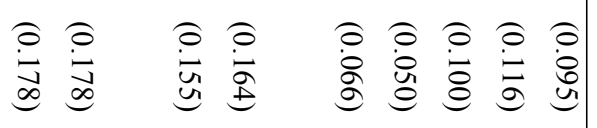

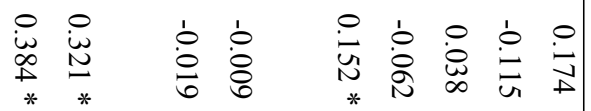

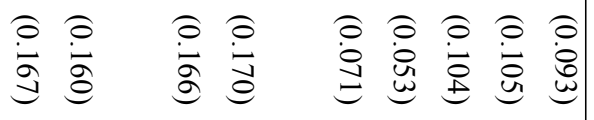

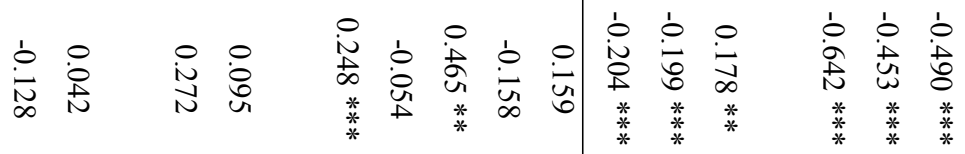

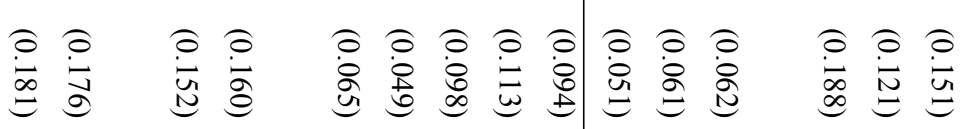

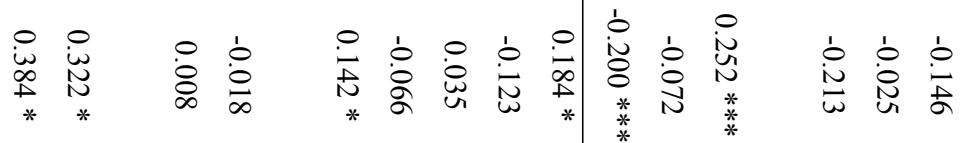

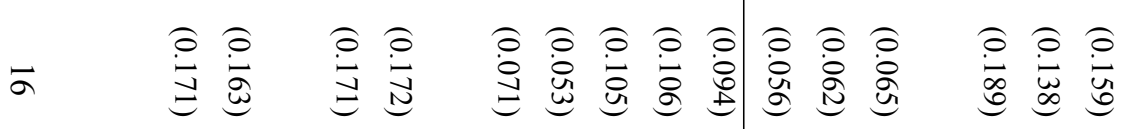




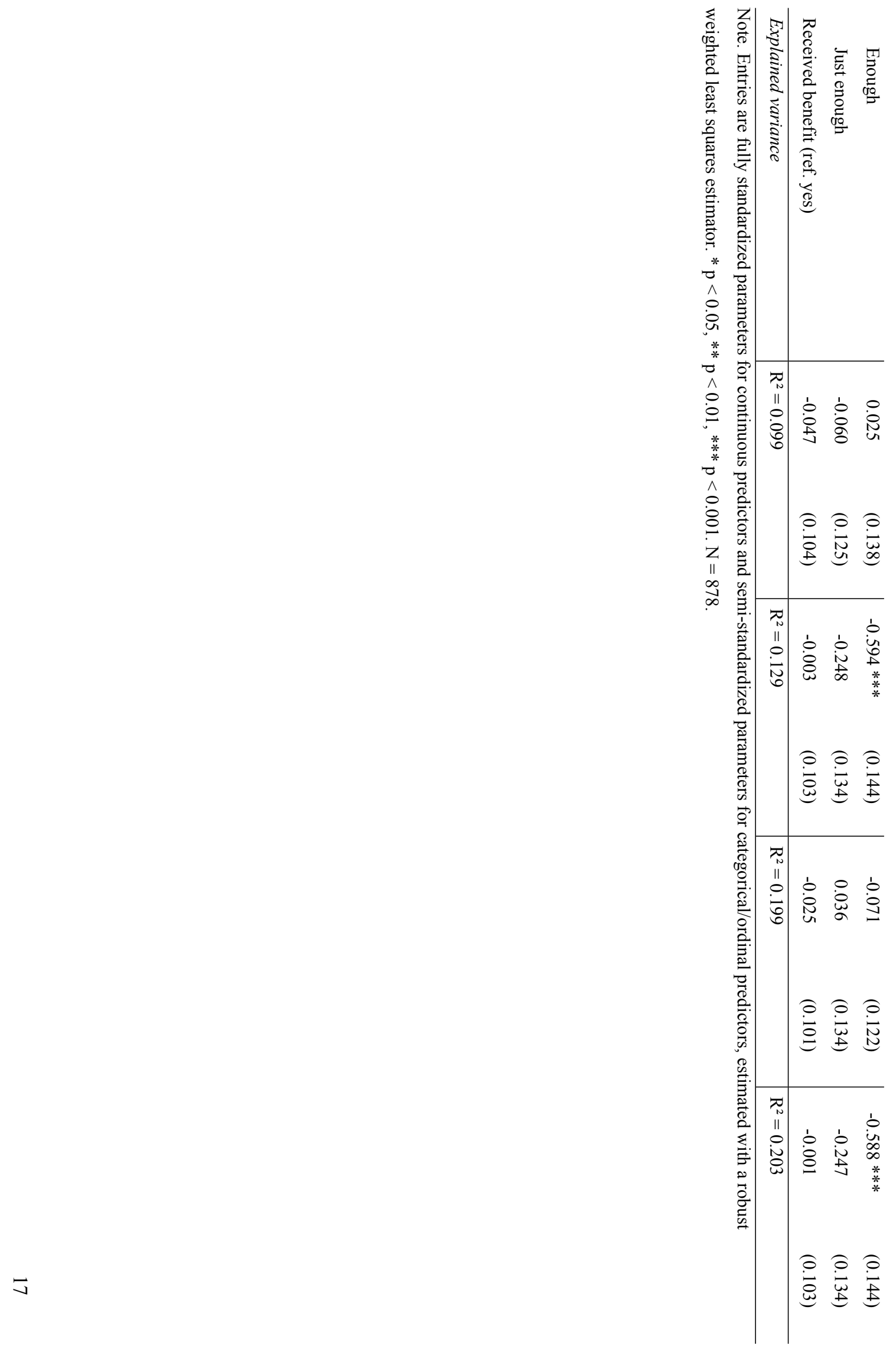




\section{Discussion}

The main goal of this article was to investigate to what extent perceptions of unfair treatment and national and/or ethnic identities can explain why some established ethnic minority group members hold anti-immigrant attitudes. Given the dual position of established minorities in society, we expected an interplay of threat and solidarity mechanisms: do feelings of discrimination and national versus ethnic identification result in a logic of solidarity or threat regarding new immigrants? To answer this question, we investigated the anti-immigrant attitudes of two established ethnic minority groups - namely Belgians of Turkish and Moroccan descent - and hypothesized that depending on their relative group position vis-à-vis the new immigrant groups we could expect either a logic of interminority threat and conflict (generating a negative attitude toward new immigrants) or a logic of solidarity (fostering positive attitudes toward new immigrants). Overall, four findings stand out. First, established ethnic minorities are not exempt from prejudice toward newcomers. Just as Belgian natives, a number of Belgians of Turkish and Moroccan descent display hostile sentiments about the influx of new migrants. Attitudes are more negative when Eastern European immigrants are concerned, probably because Eastern Europeans are, from the perspective of Moroccan and Turkish Belgians, a culturally distant and economically threatening outgroup. While some Belgians of Turkish and Moroccan descent may see 'new migrants' as a superordinate ethnic ingroup to which new immigrants coming from Turkey and Morocco may belong as well, Eastern Europeans are a clearly specified ethnic outgroup which is more likely to induce thinking in terms of group categorization and 'us versus them'.

Second, feelings of unfair treatment are important for understanding anti-immigrant attitudes among ethnic minorities. More than $14 \%$ of the variance in anti-immigrant attitudes could be explained by means of these indicators. Interestingly, however, the direction of the relationship between unfair treatment and anti-immigrant attitudes depends on the specific setting and figuration, that is, whether discrimination and deprivation are experienced in the labor market, in interaction with governmental institutions or in daily encounters with fellow citizens. Feelings of unfair treatment by political institutions and experiences of discrimination in daily life are interpreted in terms of an antagonistic native majority $v s$. non-native minority conflict activating a logic of solidarity, uniting ethnic minorities in their disadvantaged position against the dominant society. These experiences seem to remind the established ethnic minorities of their shared subordinate position with newcomers, compared to the politically dominant native group. Feelings of relative deprivation in the labor market, on the other hand, have the opposite effect. Being unfairly treated in the labor market has immediate consequences for the economic and material well-being of the established ethnic minorities. This zero-sum figuration opposes different groups beyond the majority-minority divide and activates feelings of competition for the same scare resources as jobs and a secure labor market position. For ethnic minorities in particular, this means that they may be in direct competition with each other, as they usually compete for jobs on the secondary segments of the labor market that require the same kind of qualifications and 
competences. Following a logic of threat, labor-market related relative deprivation indeed fosters antiimmigrant attitudes, especially when Eastern Europeans are the target. Feelings of deprivation and discrimination thus not only affect ethnic minorities' individual well-being (De Vroome \& Hooghe, 2013; Pascoe \& Richman, 2009) and civic engagement (De Vroome, Hooghe, \& Marien, 2013; WrayLake, Syvertsen, \& Flanagan, 2008), it plays a significant role for interminority relations as well. Extending existing knowledge on the relationship between unfair treatment and prejudice (e.g., Just \& Anderson, 2015; Sarrasin et al., 2018), our results make clear that this relationship can vary fundamentally depending on the domain of discrimination/deprivation and the group of comparison at stake.

Third, ethnic minorities who feel more closely connected to the host society than to their country of origin, seem to hold more negative attitudes toward the arrival of new immigrants. Interestingly, in our sample, identification was only significantly linked with attitudes towards new migrants in general, and not toward Eastern Europeans in particular. As mentioned before, the broad category of 'new migrants' might include migrants of the same country of origin as the respondents in this study - in opposition to the category of 'Eastern Europeans'. In that sense, it is not surprising that longer residing ethnic minorities who still feel closely connected to the country of origin are more tolerant toward new migrants in general than ethnic minorities who identify fully with the host country. This logic of solidarity does not apply for attitudes toward Eastern Europeans, a clearly distinct ethnic group. The implication of this result is ambiguous: integration and assimilation increase individual prospects of ethnic minorities in the host country, but at the same time, a stronger national identity also augments polarization and animosity between disadvantaged minority groups.

Fourth, not all previously validated prejudice mechanisms operating among majority groups simply translate to ethnic minority groups as well. Especially with regard to socio-economic position measured by education level and income insecurity - no direct relationship with anti-immigrant attitudes was observed. This might be explained by the fact that our sample shows relatively little variation in socio-economic positions - the majority of the respondents is situated at the lower end of the social ladder. Furthermore, according to the so-called integration paradox (ten Teije, Coenders, \& Verkuyten, 2013), the economically more integrated and more highly educated minorities can be more perceptive of unfair treatment and discrimination, which might block the anti-immigrant inducing effects of low socio-economic status. Further research is needed to shed more light on the differences in effects of these classical predictors between majority and minority groups.

A novelty of our study is that it differentiates between two targets of prejudice, new immigrants in general and Eastern Europeans in particular. This approach allows to examine whether attitudes toward different ethnic outgroups may be triggered by different mechanisms, depending on the group position of the bigot and target. The differentiated threat logic (see Meuleman et al., 2018) is indeed confirmed: 
explanatory models of prejudice are not 'one size fits all' models, but should be nuanced depending on the particular intergroup context. As hypothesized, feelings of unfair treatment in the labor market were more strongly related to Eastern European attitudes compared to attitudes toward new migrants in general, while the reverse was found for feelings of unfair treatment by governmental institutions. Thus, while the logic of threat prevailed for the evaluation of Eastern Europeans, the logic of solidarity was more pronounced for the evaluation of immigrants in general.

One limitation of this study is the bias in the sampling frame. As ethnic minorities were selected based on the municipal population registers, only Turks and Moroccans with Belgian nationality could be selected. As such, our respondents are already formally integrated in Belgian society and might perceive themselves as established outsiders, which might have affected the results. Citizenship aligns the attitudes of natives and newcomers and nurtures instrumental considerations such as the desire to restrict social benefits only to citizens (Just \& Anderson, 2015; Kolbe \& Crepaz, 2016). Citizenship thus might make the established ethnic minorities less enthusiastic about new immigration compared to minorities without Belgian citizenship, overestimating the negativity of interminority relations. A second limitation is the measure of target specific anti-immigrant attitudes. Ideally, we would have measured attitudes toward a broader variety of ethnic outgroups and made use of a more fine-grained set of items. Our measure of attitudes toward 'immigrants in general' could also capture a more general attitude toward migration policy and closed border policy. Another venue for future research is to study the relationship between feelings of unfair treatment by other minority groups (even the Turkish vs. the Moroccan group) and different types of anti-immigrant attitudes.

To conclude, our results confirm that there is no apparent reason why well-established ethnic minority groups would be exempt from exclusionist attitudes toward new immigrants. We investigated the explanatory power of perceptions of unfair treatment and identification and found that both the group conflict/social identity (predicting negative attitudes) and solidarity (predicting positive attitudes) framework apply to explain interminority attitudes. Which logic gains upper hand depends crucially on the specific setting of unfair treatment. While deprivation on the labor market and identification with the host country stimulates interminority hostily (logic of threat), experiences of discrimination by the government or in daily life lead to positive attitudes towards newcomers (logic of solidarity). Moreover, the strength of these relationships were idiosyncratic to the ingroup-outgroup constellation under study. In that sense, intergroup attitudes not only depend on the cultural and economic position of the groups, but also on the specific ingroup-outgroup configuration in which the conflict takes place. 


\section{References}

Abts, K., \& Kochuyt, T. (2013). De vreemde bedreiging van de verzorgingsstaat. Tijdschrift Voor Sociologie, 34(3), 227-249.

Alanya, A., Swyngedouw, M., Vandezande, V., \& Phalet, K. (2017). Close encounters: Minority and majority perceptions of discrimination and intergroup relations in Antwerp, Belgium. International Migration Review, 51(1), 191-217.

Blumer, H. (1958). Race prejudice as a sense of group position. The Pacific Sociological Review, $1(1), 3-7$.

Bobo, L. (1983). Whites' opposition to busing: Symbolic racism or realistic group conflict? Journal of Personality and Social Psychology, 45, 1196-1210.

Brylka, A., Jasinskaja-Lahti, I., \& Mähönen, T. A. (2016). The majority influence on interminority attitudes: The secondary transfer effect of positive and negative contact. International Journal of Intercultural Relations, 50, 76-88.

Callens, M.-S., Valentová, M., \& Meuleman, B. (2014). Do attitudes towards the integration of immigrants change over time? A comparative study of natives, second-generation immigrants and foreign-born residents in Luxembourg. Journal of International Migration and Integration, 15(1), 135-157.

Coenders, M., Boog, I., \& Dinsbach, W. (2010). Discriminatie-ervaringen: een onderzoek naar ervaren discriminatie op grond van land van herkomst, geloof en huidskleur. In I. Boog \& W. Dinsbach (Eds.), Monitor Rassendiscriminatie (pp. 33-74). Landelijk expertisecentrum.

Corluy, V., Haemels, J., Marx, I., \& Verbist, G. (2015). The labour market position of secondgeneration immigrants in Belgium. Brussels.

Cortland, C. I., Craig, M. A., Shapiro, J. R., Richeson, J. A., Neel, R., \& Goldstein, N. J. (2017). Solidarity through shared disadvantage: Highlighting shared experiences of discrimination improves relations between stigmatized groups. Interpersonal Relations and Group Processes, 113(4), 547-567.

Craig, M. A., \& Richeson, J. A. (2012). Coalition or derogation? How perceived discrimination influences intraminority intergroup relations. Journal of Personality and Social Psychology, 102, 759-777.

Craig, M. A., \& Richeson, J. A. (2016). Stigma-based solidarity: Understanding the psychological foundations of conflict and coalition among members of different stigmatized groups. Current Directions in Psychological Science, 25(1), 21-27. 
De Vroome, T. (2013). Earning your place. The relation between immigrants' economic and psychological integration in the Netherlands. Universiteit Utrecht.

De Vroome, T., \& Hooghe, M. (2013). Life satisfaction among ethnic minorities in the Netherlands: Immigration experience or adverse living conditions? Journal of Happiness Studies.

De Vroome, T., Hooghe, M., \& Marien, S. (2013). The origins of generalized and political trust among immigrant minorities and the majority population in the Netherlands. European Sociological Review, 29(6), 1336-1350.

Duckitt, J. (1992). The social psychology of prejuice. New York, NY: Praeger Publishers.

Esser, H. (2003). What substance is there in the term "Leitkultur”? In R. Cuperus, K. A. Duffek, \& J. Kandel (Eds.), The challenge of diversity (pp. 47-58). Innsbruck: Studienverlag.

Feldman, S. (2015). Attitudes, Political: Authoritarianism and Tolerance. International Encyclopedia of the Social \& Behavioral Sciences (Second Edi, Vol. 2). Elsevier.

Fleischmann, F., \& Phalet, K. (2016). Identity Conflict or Compatibility: A Comparison of Muslim Minorities in Five European Cities. Political Psychology, 37(4), 447-463.

Foner, N., Duyvendak, J. W., \& Kasinitz, P. (2019). Introduction: super-diversity in everyday life. Ethnic and Racial Studies, 42(1), 1-16.

Gay, C. (2006). Seeing difference: The effect of economic disparity on Black attitudes toward Latinos. Americal Journal of Political Science, 50(4), 982-997.

Gorodzeisky, A., \& Glikman, A. (2018). Two peoples - two stories: Anti-immigrant attitudes in PostSocialist Russia. Social Problems, 65, 543-563.

Gsir, S., Mandin, J., \& Mescoli, E. (2015). Corridor Report on Belgium Moroccan and Turkish Immigration in Belgium. INTERACT Research Report 2015/03. San Domenico di Fiesole (FI): European University Institute.

Hagendoorn, L. (1995). Intergroup biases in multiple group systems: The perception of ethnic hierarchies. European Review of Social Psychology, 6(1), 199-228.

Heath, A. F., Fisher, S. D., Rosenblatt, G., Sanders, D., \& Sobolewska, M. (2013). The Political Integration of Ethnic Minorities in britain. Oxford: Oxford University Press.

Hellwig, T., \& Sinno, A. (2017). Different groups, different threats: public attitudes toward immigrants. Journal of Ethnic and Migration Studies, 43(3), 339-358.

Hindriks, P., Verkuyten, M., \& Coenders, M. (2014). Interminority attitudes: The roles of ethnic and national identification, contact, and multiculturalism. Social Psychology Quarterly, 77(1), 54- 
74.

Hindriks, P., Verkuyten, M., \& Coenders, M. (2015). The evaluation of immigrants' political acculturation strategies. International Journal of Intercultural Relations, 47, 131-142.

Hindriks, P., Verkuyten, M., \& Coenders, M. (2017). Evaluating political acculturation strategies: The perspective of the majority and other minority groups. Political Psychology, 38(5), 741-756.

Hooghe, M., Trappers, A., Meuleman, B., \& Reeskens, T. (2008). Migration to European countries: A structural explanation of patterns, 1980-2004. IMR: International Migration Review, 42(2), 476504.

Huber, P., \& Oberdabernig, D. A. (2016). The impact of welfare benefits on natives' and immigrants' attitudes toward immigration. European Journal of Political Economy, 44, 53-78.

Jackson, J. (1993). Realistic Group Conflict Theory: A review and evaluation of the theoretical and empirical literature. The Psychological Record, 43, 395-413.

Jacobs, D., Phalet, K., \& Swyngedouw, M. (2004). Associational membership and political involvement among ethnic minority groups in Brussels. Journal of Ethnic and Migration Studies, 30(3), 543-559.

Just, A., \& Anderson, C. J. (2015). Dual allegiances? Immigrants' attitudes toward immigration. The Journal of Politics, 77(1), 188-201.

Kolbe, M., \& Crepaz, M. M. L. (2016). The power of citizenship: How immigrant incorporation affects attitudes towards social benefits. Comparative Politics, 49(1), 105-123.

Lafleur, J.-M., \& Marfouk, A. (2018). Migratie in België. 21 vragen en antwoorden. Leuven: Universitaire Pers Leuven.

Meeusen, C., \& Jacobs, L. (2017). Television news content of minority groups as an intergroup context indicator of differences between target-specific prejudices. Mass Communication and Society, 20(2), 213-240.

Meeusen, C., \& Kern, A. (2016). The effect of contextual factors on the association between different forms of prejudice : a cross-national approach on generalized prejudice. Social Science Research, 55, 1-15.

Meuleman, B., Abts, K., Slootmaeckers, K., \& Meeusen, C. (2018). Differentiated threat and the genesis of prejudice: Groupspecific antecedents of homonegativity, Islamophobia, antiSemitism and anti-immigrant attitudes. Social Problems. doi.org/10.1093/socpro/spy002 Meuleman, B., \& Billiet, J. (2003). De houding van Vlamingen tegenover "oude" en "nieuwe" 
migranten: diffuus of specifiek? In Vlaanderen gepeild (pp. 137-176). Brussel: APS (Ministerie van de Vlaamse Gemeenschap).

Monteith, M. J., \& Spicer, C. V. (2000). Contents and correlates of Whites' and Blacks' racial attitudes. Journal of Experimental Social Psychology, 36, 125-154.

Mustafa, A., \& Richards, L. (2018). Immigration attitudes amongst European Muslims: Social identity, economic threat and familiar experiences. Ethnic and Racial Studies. https://doi.org/10.1080/01419870.2018.1472387

Myria. (2017). Migratie in cijfers en rechten. Jaarlijks rapport. Brussels.

Oliver, J. E., \& Wong, J. (2003). Intergroup prejudice in multiethnic settings. American Journal of Political Science, 47(4), 567-582.

Pascoe, E. A., \& Richman, L. S. (2009). Perceived discrimination and health: A meta-analytic review. Psychological Bulletinh, 135(4), 531-554.

Pettigrew, T. F., Christ, O., Wagner, U., Meertens, R. W., van Dick, R., \& Zick, A. (2008). Relative deprivation and intergroup prejudice. Journal of Social Issues, 64(2), 385-401.

Phalet, K., \& Swyngedouw, M. (2003). Measuring immigrant integration: The case of Belgium. Migration Studies, 40(152), 773-803.

Philip, C. L., Mahalingam, R., \& Sellers, R. M. (2010). Understanding East Indians' attitudes toward African Americans: Do mainstream prejudicial attitudes transfer to immigrants? Journal of Ethnic and Migration Studies, 36(4), 651-671.

Runciman, W. G. (1966). Relative deprivation and social justice: A study of attitudes to social inequality in twentieth century England. Berkeley: University of California Press.

Sarrasin, O., Green, E. G. T., Bolzman, C., Visintin, E. P., \& Politi, E. (2018). Competition- and identity-based roots of anti-immigration prejudice among individuals with and without an immigrant background. International Review of Social Psychology, 31(1), 1-12.

Sarrasin, O., Green, E. G. T., Fasel, N., \& Davidov, E. (2015). Does survey respondents' immigrant background affect the measurement and prediction of immigration attitudes? An illustration in two steps. International Journal of Public Opinion Research, 27(2), 264-276.

Semyonov, M., Raijman, R., \& Yom-Tov, A. (2002). Labor market competition, perceived threat, and endorsement of economic discrimination against foreign workers in Israel. Social Problems, 49(3), 416-431.

Sirin, C. V., Valentino, N. A., \& Villalobos, J. D. (2016). Group Empathy Theory: The effect of group 
empathy on U.S. intergroup attitudesand behavior in the context of immigration threats. Journal of Politics, 78(3), 893-908.

Sirin, C. V., Valentino, N. A., \& Villalobos, J. D. (2017). The social causes and political consequences of group empathy. Political Psychology, 38(3), 427-448.

Staerklé, C., Sidanius, J., Green, E. G. T., \& Molina, L. (2005). Ethnic minority-majority asymmetry and attitudes towards immigrants across 11 nations. Psicología Política, 30, 7-26.

Swyngedouw, M., Meuleman, B., Abts, K., Bousetta, H., \& Galle, J. (2015). Belgian Ethnic Minorities Election Study 2014. Codebook: Questions and Frequency Tables. Leuven: ISPO-KU Leuven \& CLEO/CEDEM-Université de Liège.

[Dataset] Swyngedouw, M., Meuleman, B., Abts, K., Bousetta, H., \& Galle, J. (2015). Belgian Ethnic Minorities Election Study 2014. Dataset. Leuven: ISPO-KU Leuven \& CLEO/CEDEMUniversité de Liège.

ten Teije, I., Coenders, M., \& Verkuyten, M. (2013). The paradox of integration: Educational attainment and immigrants' attitudes towards the native population. Social Psychology, 44, 278288.

Timmerman, C., Vanderwaeren, E., \& Crul, M. (2003). The second generation in Belgium. International Migration Review, 37(4), 1065-1090.

Tropp, L. R., \& Pettigrew, T. F. (2005). Relationships between intergroup contact and prejudice among minority and majority status groups. Psychological Science, 16(12), 951-957.

Van der Zwan, R., Bles, P., \& Lubbers, M. (2017). Perceived migrant threat among migrants in Europe. European Sociological Review, 33(4), 518-533.

Vandezande, V., Fleischmann, F., Baysu, G., Swyngedouw, M., \& Phalet, K. (2009). Ongelijke kansen en ervaren discriminatie in de Turkse en Marokkaanse tweede generatie. Leuven.

Valentova, M., \& Berzosa, G. (2012). Attitudes toward immigrants in Luxembourg. Do contacts matter? International Review of Sociology, 22(2), 341-363.

Van Pottelberge, A., \& Lievens, J. (2017). Gevoelens van etnische vooroordelen bij Turkse Vlamingen. In welke mate zijn ze gelinkt aan ouderlijke voorkeuren in partnerkeuze? Sociologos, 38(1-2), 163-187.

Verkuyten, M., \& Martinovic, B. (2012). Immigrants' national identification: Meanings, determinants, and consequences. Social Issues and Policy Review, 6(1), 82-112.

Verkuyten, M., \& Martinovic, B. (2016). Dual identity, in-group projection, and out-group feelings 
among ethnic minority groups. European Journal of Social Psychology, 46, 1-12.

Vertovec, S. (2007). Super-diversity and its implications. Ethnic and Racial Studies, 30(6), 1024 1054.

Wray-Lake, L., Syvertsen, A. K., \& Flanagan, C. A. (2008). Contested citizenship and social exclusion: Adolescent Arab American immigrants' views of the social contract. Applied Developmental Science, 12(2), 84-92. 


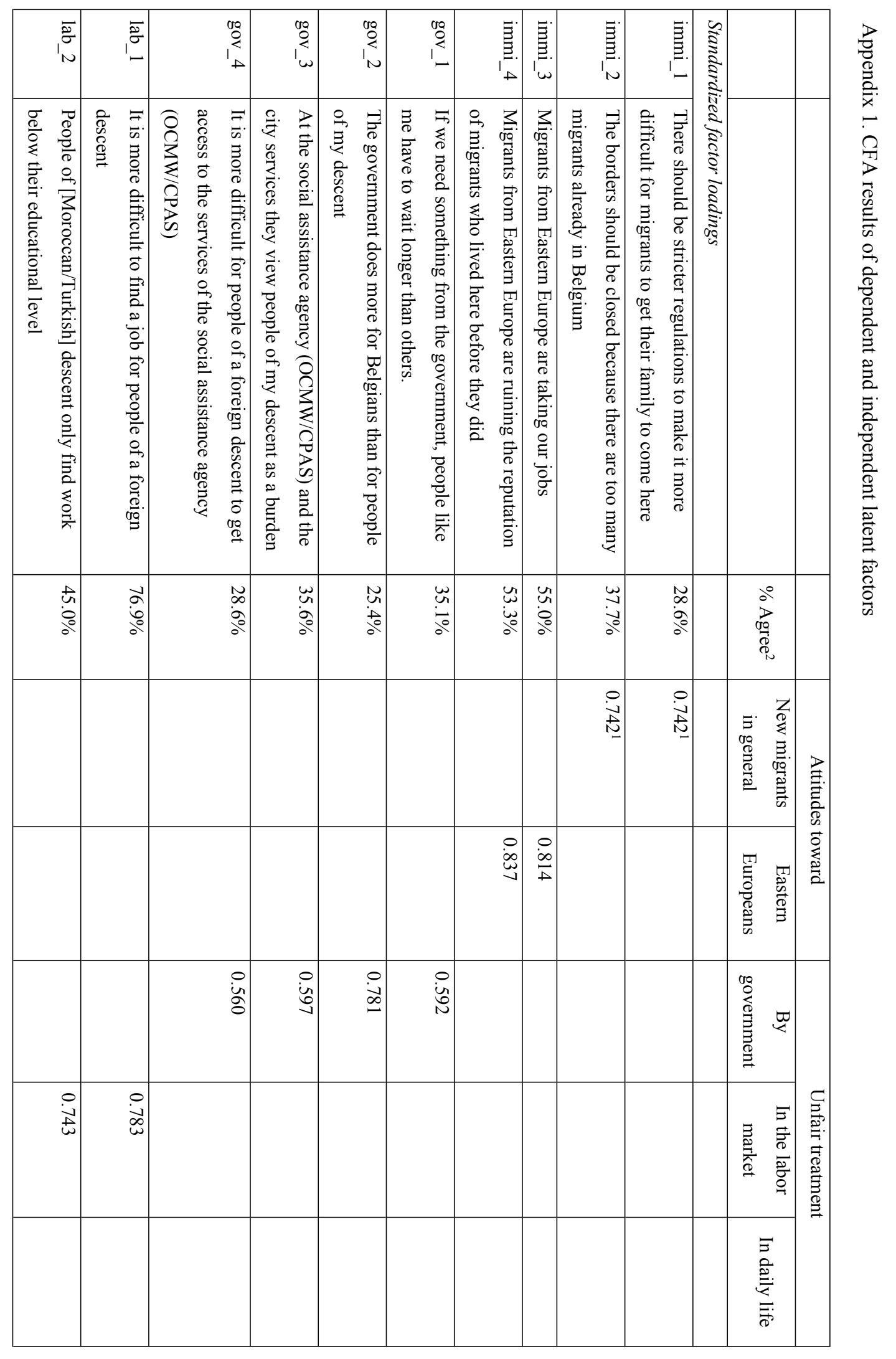




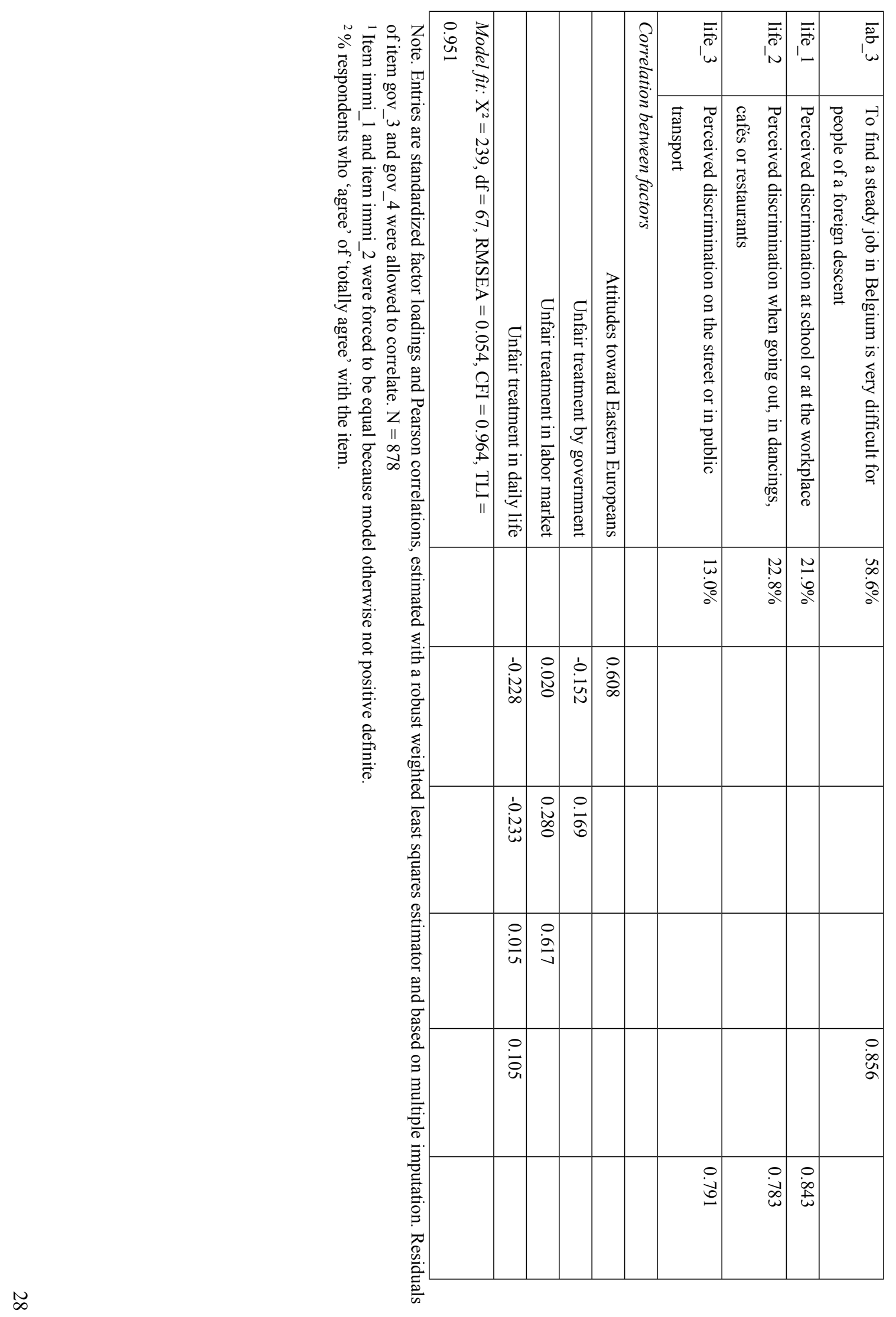

